\title{
ANÁliSE MINERALÓGICA DOS PLANOSSOLOS NO MUNICÍPIO DE CURAÇÁ- BA E SEU POTENCIAL NATURAL DE FERTILIZAÇÃO
}

\author{
SANTOS, Jonathas J. ${ }^{1}$; CHAVES, Joselisa M. ${ }^{2}$ \\ 1. Bolsista PIBIC/FAPESB, Graduando em Bacharelado em Geografia, Universidade Estadual de Feira de Santana, e-mail: \\ jonathas020@hotmail.com \\ 2. Orientadora, Departamento de Ciências Exatas, Universidade Estadual de Feira de Santana, e-mail: joselisa@uefs.br
}

PALAVRAS-CHAVE: Sensoriamento Remoto; Solo; Fertilidade Natural.

\section{INTRODUÇÃO}

O estudo sobre os solos através da espectrorradiometria é fundamental para compreender os diferentes processos que acontecem no meio natural, ressaltando importância desses processos para os seres vivos. Através da espectrorradiometria, pode-se observar o comportamento espectral dos Planossolos identificando sua assinatura espectral. Nesse contexto, observando a assinatura espectral verifica-se a absorção dos diferentes tipos de minerais constituintes, assim, pode-se inferir o potencial natural de fertilização, uma vez que os minerais são macro e micronutrientes para a fertilidade natural dos solos. De acordo com Florenzano (2008), o Sensoriamento Remoto é a tecnologia que permite obter imagens e outros tipos de dados, da superfície terrestre, por meio da captação e do registro da energia refletida ou emitida pela superfície. Segundo Demattê (2014), a espectrorradiometria é amplamente utilizada na caracterização do comportamento espectral dos solos. Sendo assim, observa-se a importância da espectrorradiometria na investigação dos solos, uma vez que pode-se obter resultados precisos que colaboram com o estudo. Os Planossolos ocorrem tipicamente em áreas de cotas baixas, planas a suave onduladas. São, geralmente, pouco profundos, com horizonte superficial de cores claras e textura arenosa ou média (leve), seguido de um horizonte B plânico (horizonte característicos dos planossolos) (EMBRAPA 2016). Segundo Guerra (2015), a fertilidade natural do solo é consequência dos processos que o originaram, são estes processos: o material de origem, ambiente, organismos, tempo e relevo. Logo, o trabalho tem como objetivo geral caracterizar os minerais presentes nos horizontes dos Planossolos em Curaçá-BA e inferir o seu potencial natural de fertilização. Como objetivos específicos, pretendeu-se identificar e caracterizar os fatores de formação dos Planossolos em Curaçá-BA; medir o comportamento espectral do Planossolos mediante técnicas de espectrorradiometria de reflectância.

\section{MATERIAL E MÉTODOS}

A área de estudo localiza-se no município de Curaçá-BA (Figura 1). Para que os resultados fossem alcançados, foram seguidas as etapas metodológicas de pesquisa: inicialmente um referencial teórico sobre gênese dos Planossolos e o seu potencial de fertilização natural, compreensão da presença dos minerais e potencialidade dos mesmo para fertilização dos solos, sensoriamento remoto e espectrorradiometria. Logo em seguida, geração dos dados geoambientais da área de estudo para melhor compreender a geodinâmica das áreas de Planossolos e os seus fatores de formação. O trabalho de campo veio logo depois, com coleta 
de amostras de Planossolos no município de Curaçá-BA. As amostras colhidas foram destorroadas (retirando as grandes frações do solo) e secadas na estufa por $45^{\circ}$ celsos por 24 horas. A análise do comportamento espectral dos Planossolos foi realizada com o aparelho portátil FieldSpec®4 Hi-Res (450-2500nm) / A100590 pertencente ao laboratório de espectrorradiometria (LABESPECTRO) do Programa de Pós-Graduação em Modelagem em Ciências da Terra e do Ambiente (PPGM), localizado na Universidade Estadual de Feira de Santana (UEFS). Logo depois a comparação das curvas espectrais e identificação de minerais. Nesse sentido, foi possível identificar os macros e micronutrientes presentes nos Planossolos uma vez identificados os minerais constituintes. Por fim, foi avaliado o potencial natural de fertilização dos Planossolos.

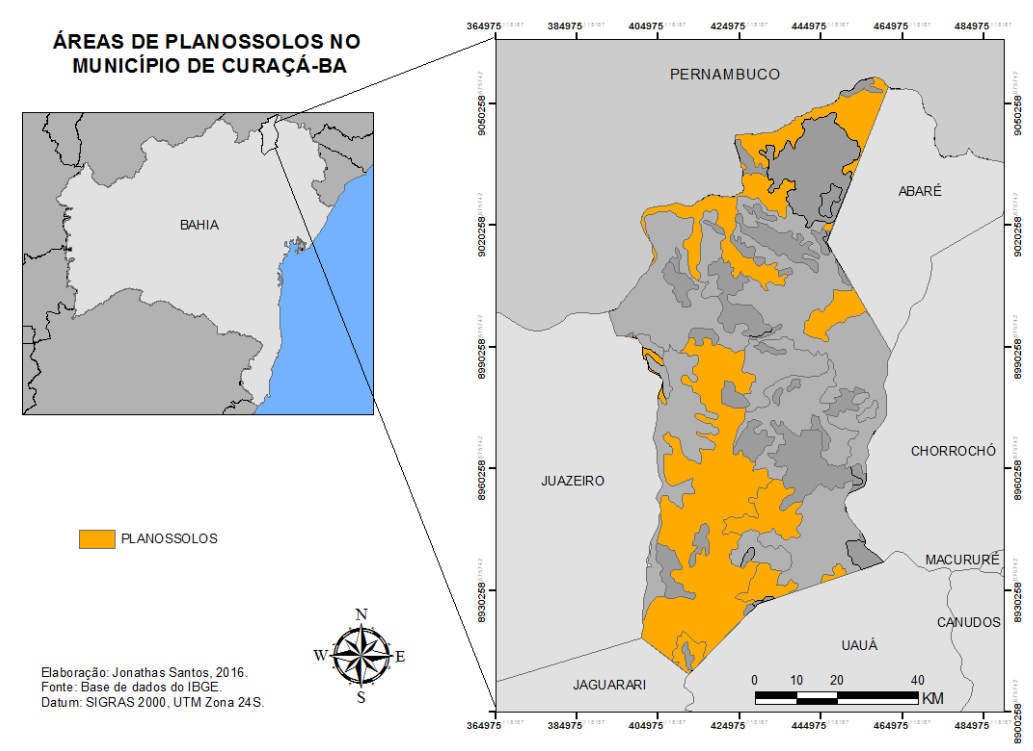

Figura 1: Localização da área de estudo

\section{RESULTADOS E DISCUSSÃO}

Com a avaliação dos fatores de formação dos Planossolos (Tabela 1), verificou-se que o material de origem revela uma constituição litológica composta basicamente por rochas metamórficas. Já o ambiente, de clima semiárido, com precipitação média anual de $461 \mathrm{~mm}$, revela uma irregularidade de chuvas nessa região. As presenças de organismos adaptados a caatinga ajudariam e acelerariam o processo de formação do solo. O tempo de formação que seria da época holocênica revelam um tipo de formação de solo mais recente (em milhões de anos). O relevo dessa região, especialmente das áreas de Planossolos, é composto basicamente por uma topografia mais plana em decorrência dos processos de pediplanação aliado ao clima semiárido, favorecendo a formação dos Planossolos. Nesse contexto, todos esses processos originaram os Planossolos de Curaçá-BA favorecendo a formação de minerais típicos de regiões semiáridas. Consequentemente o seu potencial natural de fertilização é decorrente de sua pedogênese levando a um determinado tipo de conteúdo mineral com macro e micronutrientes naturais. 
Tabela 1. Fatores de formação dos Planossolos de Curaçá-BA

\begin{tabular}{|c|c|c|c|c|}
\hline $\begin{array}{c}\text { MATERIAL DE } \\
\text { ORIGEM }\end{array}$ & AMBIENTE & ORGANISMOS & TEMPO & RELEVO \\
\hline $\begin{array}{c}\text { Anfibolito, } \\
\text { Metagranito, } \\
\text { Metagranodiorito, } \\
\text { Migmatito, } \\
\text { Metagrauvaca }\end{array}$ & $\begin{array}{c}\text { Clima semiárido } \\
\text { com precipitação } \\
\text { média anual de } \\
461 \mathrm{~mm} .\end{array}$ & $\begin{array}{c}\text { Presença da } \\
\text { caatinga } \\
\text { arbustiva e } \\
\text { caatinga parque, } \\
\text { com fauna e flora } \\
\text { adaptados ao } \\
\text { clima semiárido. }\end{array}$ & $\begin{array}{c}\text { Período } \\
\text { Quaternário, } \\
\text { época } \\
\text { holocênica }\end{array}$ & $\begin{array}{c}\text { Pedimentos } \\
\text { funcionais } \\
\text { ou retocados } \\
\text { por } \\
\text { drenagem } \\
\text { incipiente. } \\
\text { (Relevos } \\
\text { planos) }\end{array}$ \\
& & & & \\
\end{tabular}

Com as análises espectrorradiométricas dos Planossolos de Curaçá-BA foi possível identificar os principais minerais existentes nos solos dessa região (Figuras 2 e 3). Com a identificação dos minerais, pode-se inferir o potencial natural de fertilização. A Montmorilonita é um dos mineiras mais presentes nos Planossolos de Curaçá, fonte de macronutrientes secundários, como o Magnésio (Mg), que de acordo com Coelho (1973) é um dos constituintes das clorofilas das plantas. O magnésio é absorvido como íon bivalente positivo ( $\mathrm{Mg++}$. Compõe a molécula de clorofila, que dá a cor verde às plantas. A clorofila contém cerca de $2,7 \%$ de magnésio. (SENGIK, 2003, p. 4).

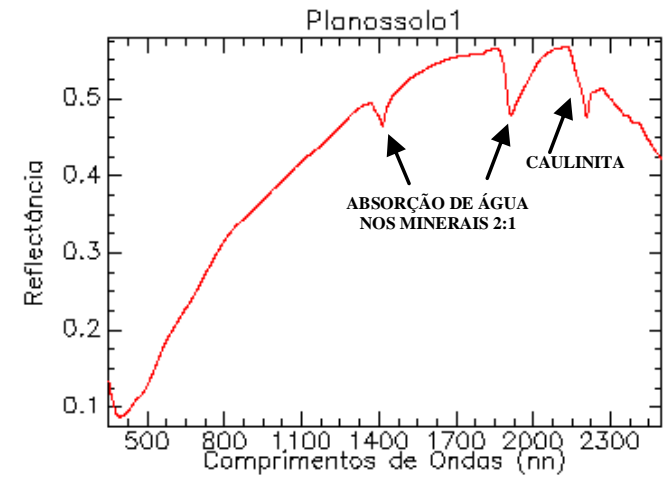

Figura 2: Espectro da amostra 1 de Planossolo

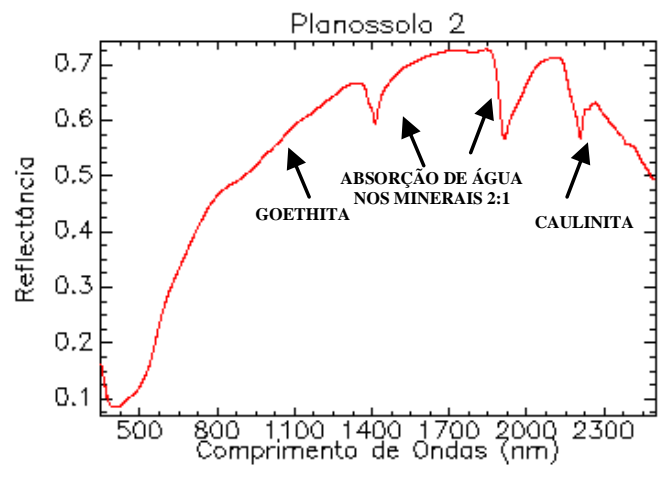

Figura 3: Espectro da amostra 2 de Planossolo

Outro mineral encontrado nas amostras foi a Goethita $\mathrm{Fe}^{3+} \mathrm{O}(\mathrm{OH})$, que contém em sua composição o elemento químico Ferro. Nesse sentido, Coelho (1973) relata que o Ferro é um micronutriente no solo, uma das principais funções na planta é agir como um catalisador na produção de clorofila. O Cálcio também encontrado no mineral montmorilota bem como na Calcita (outro mineral também presente nas amostras de planossolo de Curaçá), de acordo com Coelho (1973) é um macrunutriente secundário, em que as diferentes espécies de plantas extraem diferentes quantidades de Cálcio. A quantidade absoluta de cálcio trocável presente no solo, frequentemente é menos importante para a nutrição das plantas do que o seu conteúdo em relação às quantidades e tipos dos outros íons presentes no solo (COELHO, 1973). 


\section{CONSIDERAÇÕES FINAIS}

Este estudo foi fundamental para melhor compreender o potencial natural de fertilização dos Planossolos de Curaçá-BA utilizando técnicas de espectrorradiometria. Nesse contexto, observa-se que os fatores de formação dos Planossolos de Curaçá BA são os responsáveis por sua fertilidade natural. Verifica-se que os Planossolos de Curaçá-BA é um solo típico do semiárido apresentando minerais também típicos dessa região. Nesse sentido, as análises espectrorrradiométricas identificaram pouca variação de conteúdo mineral nas diferentes amostras de Planossolo, revelando os macros e micronutrientes através da identificação de minerais. Nesse contexto, a pouca variação mineralógica leva-se a inferir o potencial de fertilização natural para as classes de Planossolos desse município, relevando um médio abaixo potencial, uma vez que contém mais macronutrientes secundários em contraposição a micronutrientes. Logo, essa pesquisa foi significativa, uma vez que através de técnicas de Sensoriamento Remoto identificou-se o potencial natural de fertilização dos solos de CuraçáBA, uma área carente em estudos de potencial de fertilização dos solos.

\section{REFERÊNCIAS}

COELHO, F. S. Fertilidade do solo. Campinas: Instituto Campineiro de Ensino Agrícola, 1973.

DEMATTÊ, José A. M. AlVES, Marcelo R. GALHO, Bruna C. FONGARO, Caio T. Detecção de limites de solos por dados espectrais e de relevo. SBCS, 2014.

EMBRAPA. Planossolos. Disponível em: <http://www.agencia.cnptia.embrapa.br/gestor/bioma_caatinga/arvore/CONT000g5twggzh02 wx5ok01edq5s189t6ux.htmll> Acesso em 20.03.2016.

FLORENZANO, T. G. (org.). Geomorfologia: conceitos e tecnologias atuais. São Paulo: Oficina de Textos, 2008.

GUERRA, Wellington E. X. Fertilidade do solo. Presidente Prudente - SP: GPAGRO, Comunicado técnico, 2015.

SENGIK, É. S. Uma visão global de solos. Maringá: NUPEL-UEM, 2003. 